\title{
Dual objective multiconstraint swarm optimization based advanced economic load dispatch
}

\author{
Himanshu Shekhar Maharana, Saroj Kumar Dash \\ Gandhi Institute for Technological Advancement, Bhubaneswar, 752054, India
}

\begin{tabular}{l} 
Article Info \\
\hline Article history: \\
Received Nov 15, 2019 \\
Revised Dec 9, 2020 \\
Accepted Dec 16, 2020 \\
\hline
\end{tabular}

\section{Keywords:}

Differential evolution

Differential particle swarm optimization

Economic load dispatch Evolutionary programming Particle swarm optimization Particle swarm optimization involving inertia weight

\begin{abstract}
In electric power system, the vital topic to be mooted is economic load dispatch (ELD). It is a non-linear problem with some unavoidable constraints such as valve point loading and ramp rate constraint. For solving ELD problem distint methods were devised and tried for different electric supply systems yielding slow convergence rates. To achieve fast convergence, dual objective multi constraint swarm optimization based advanced economic load dispatch (DOMSOBAELD) algorithm is proposed making use of simulated values of real power outages of a thermal power plant as initial estimates for PSO technique embedded in it and used for optimizing economic dispatch problem in this article. DOMSOBAELD method was developed in the form of amalgamating fluids. Presence of power line losses, multiple valves in steam turbines, droop constraints and inhibited zones were utilized to optimize the ELD problem as genuinely approximate as possible. The results obtained from DOSOBAELD are compared with particle swarm optimization (PSO), PSOIW and differential particle swarm optimization (DPSO) techniques. It is quite conspicuous that DOMSOBAELD yielded minimum cost values with most favourable values of real unit outputs. Thus the proposed method proves to be advantageous over other heuristic methods and yields best solution for ELD by selecting incremental fuel cost as the decision variable and cost function as fitness function.
\end{abstract}

This is an open access article under the CC BY-SA license.

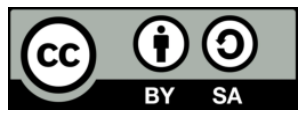

\section{Corresponding Author:}

Saroj Kumar Dash

Department of Electrical Engineering

Gandhi Institute for Technological Advancement, Madanpur, Bhubaneswar

Bijupatnaik University of Technology, Odisha, 769004-India

Email: hodeegita@gmail.com

\section{INTRODUCTION}

Due to growing complexity of the power demand the reliability, transmission loss and clear power free of distortion becomes a challenging problem for economic load dispatch (ELD). Slow convergence rate of Soft computing methods and complex computational burden with complex structural algorithm for conventional method lead to complex ELD problem. To overcome these barriers dual objective multi constraint swarm optimization based advanced economic load dispatch (DOMSOBAELD) method is applied in the proposed research work. In this paper, multiple versions of particle swarm optimization techniques are used to ascertain the optimal cost of generation capacity that can be integrated into the existing power system and the results of the proposed algorithm for a 30 bus test case system are reported. A new fictitious code based algorithm is developed, in this paper, for equality constraints [1] other than the penalty function methods that performs better due to its parallel search capability.The effect of multiple valves in steam tubines narrated by Singh and Wang et al., [2-4] yields more perturbation in cost function which can be piece wise linear using conventional economic dispatch techniques. This methodology is so easy that particle 
swarm optimization (PSO) utilizes some parameters and definitions of the optimization process and then it starts the process with an initial random population involving parallel search technique, named particles. Each of these particles has a feasible solution for the main problem and is processed as a part in ' $n$ ' dimensional space. In the variable space, each particle has a position identified by xi and a velocity identified by vi. If a particle has a best position, it is brought over to the next stage. Additionally, best positions are denoted as Pbest and the best position of all particles is denoted as Gbest. The results of generation outages for 6 units obtained through the simulation of aforesaid thermal power plant involving multiple constraints are used as initial estimates for proposed DOMSOBAELD method and final optimal schedules for real power generation, final position of swarm and their velocities are updated using PSO technique involved in DOMSOBAELD approach and are compared with various traditional methods like Lagrange multiplier method [5, 6], PSOIW, DPSO [7, 8] and sequential quadratic programming method referred in [9, 10].

\section{RESEARCH METHOD}

This section presents and formulates the objective functions viz. cost, emission and combined objective function satisfying multiconstraints involving price penalty factor $F_{i}$. The basic economic load dispatch problem incorporating valve point loading described by Sharma and Goyal et al., [11] is formulated through (1) and (2) as under;

$$
\begin{aligned}
& \left.Z_{i}=a_{i} P G_{i}^{2}+b_{i} P G_{i}+C_{i}\right)+K_{i} \sin \left(l_{i}\left(P_{i}-P G_{i}\right)\right) \\
& J_{i}=\left(h_{i} P G_{i}^{2}+g_{i} P G_{i}+q_{i}\right)
\end{aligned}
$$

where, $Z_{i}$ and $J_{i}$ are cost and emission objective functions and $a_{i}, b_{i}, c_{i}, K_{i}, l_{i}$ and $h_{i}, g_{i}, q_{i}$ are cost and emission objective function coefficients. In this dissertation the emission function involves global warming gases like $\mathrm{CO}, \mathrm{NO}_{2}$ and $\mathrm{SO}_{2}$. The final objective function $[12,13]$ formulated incorporating penalty factor $F_{i}$ is formulated in (3) as under;

$$
S_{i}=Z_{i}+F_{i} \times J_{i}
$$

where,

$$
\begin{aligned}
& F_{i}=\frac{Z_{i \max }}{J_{i \max }} \\
& \left.Z_{i}=a_{i} P G_{i}^{2}+b_{i} P G_{i}+C_{i}\right)+K_{i} \sin \left(l_{i}\left(P_{i}-P G_{i}\right)\right) \\
& J_{i}=\left(h_{i} P G_{i}^{2}+g_{i} P G_{i}+q_{i}\right)
\end{aligned}
$$

The constraints inincorporated in this work are;

a. Equality constraint

$$
\begin{aligned}
& \sum_{i-1}^{n} P G_{i}=P_{D}+T L \\
& T L=\sum_{m-1}^{6} \sum_{m-1}^{6} P G_{m} \times P G_{n} \times B_{m n}
\end{aligned}
$$

where,

$P_{D}=$ net power demand

$\mathrm{TL}=$ transmission loss.

b. Inequality constraint

$$
P_{i}<P G_{i}<P_{j}
$$

where, $P G_{i}$ represents the output power of $i^{\text {th }}$ generating unit, $P_{i}$ and $P_{j}$ are minimum and maximum output Power of $i^{\text {th }}$ generating unit respectively. 


\section{OVERVIEW OF DUAL OBJECTIVE MULTI- CONSTRAINT SWARM OPTIMIZATION \\ BASED ADVANCED ECONOMIC LOAD DISPATCH}

Particle swarm optimization [14, 15] formed the behavior of evolutionary techniques for ELD optimization. So in order to obtain optimistic results of nonlinear optimization technique, we incorporate here a ramp rate limit that outsmarts the conventional constraints through improved constriction factor based well defined ramp rate particle swarm optimization technique. This method involves differential particles $[14,15]$ in search space that randomly update their position using their velocity heuristically following their neighbors so as to obtain position and velocity vectors viz. $P_{\text {best }}, g_{\text {best }}$ i.e. $\left(P_{1 b e s t}, P_{2 b e s t} . . P_{\text {ibest }}\right)$ and $\left(g_{1 b e s t}, g_{2 b e s t}\right.$, $\left.g_{i b e s t}\right)$ respectively. The new values of position and velocity are estimated using (9) and (10).

$$
\begin{aligned}
& Y_{n 2}^{(k+1)}=\left[w Y_{n l}^{k}+A_{1} \operatorname{Rand}_{1}\left(T_{0}-S_{i}^{k}\right)+A_{2} \operatorname{Rand}_{2}\left(g_{\text {best }}-S_{i}^{k}\right)\right] \\
& \boldsymbol{S}_{n 1}^{\boldsymbol{k + 1}}=\boldsymbol{S}_{\boldsymbol{i}}^{\boldsymbol{k}}+\boldsymbol{V}_{\boldsymbol{i}}^{\boldsymbol{k}+\boldsymbol{1}}
\end{aligned}
$$

Where, $A_{1}, A_{2}$ are acceleration coefficients

$$
\begin{aligned}
& w \quad=\text { Inertia weight } \\
& Y_{n 2}^{k+1} \quad=\text { Updated velocity of the } \mathrm{k}+1 \text { iteration } \\
& T_{0} \quad=P_{\text {best }} \text { function } \\
& S_{i}^{k} \quad=\text { Initial } i^{\text {th }} \text { particle after } k^{\text {th }} \text { iteration } \\
& A_{2} \operatorname{Rand} 2\left(g_{\text {best }}-S_{i}^{k}\right)=\text { Collaboration among particles } \\
& w=w_{\text {max }}-\frac{w_{\max }-w_{\min }}{k} \times n
\end{aligned}
$$$$
S_{n 1}^{k+1} \quad=\text { Updated displacement of the k+1 iteration }
$$$$
A_{1} \operatorname{Rand} 1\left(P_{\text {best }}-S_{i}^{k}\right)=\text { Particle's Private thinking }
$$

To obtain most favourable multivalving effect the ramp rate constraints are applied upon the inequality constraints as under;

$$
\operatorname{Max}\left(P G_{i \text { min }}, P_{i 0}-D R_{i}\right) \leq P G_{\text {inew }} \leq \operatorname{Min}\left(P G_{\text {imax }}, P_{i l}+U R_{i}\right)
$$

Subject to condition

$P_{G i}-P_{i 0} \leq U R_{i}$ (Generation increases)

where,

$$
P_{i 0}-P_{i l} \leq D R_{i}(\text { Generation decreases })
$$

$P_{i 1}=$ Power generation of $i^{\text {th }}$ unit in the current interval.

DOMSOBAELD Algorithm

Step1. Initialize parameters like.

$P G_{1}, P G_{2}, P G_{3}, P G_{4}, P G_{5}, P G_{6}$

Step 2. If $\Gamma_{i}$ is better than $\Gamma_{0}$, then

$\Gamma_{i}=\Gamma_{\text {Onew }}$

Else $\Gamma_{i}=\Gamma_{0 o l d}$

Step 3. Initialize $g_{\text {best }}$ values for generating units $P G_{1}$ to $P G_{6}$ 
Step 4. Assign best of $\Gamma_{\text {inew }}$ and $\Gamma_{0 o l d}$ to $g_{\text {best }}$

Step 5. Current position $S_{i}=Z_{i}+F_{i} \times J_{i}$ and current velocity $Y_{n 1}=U_{i \min }+\operatorname{Rand} i()\left(U_{i \max }-U_{i \min }\right)$

Step 6. Update position for each particle where $Y_{n 2}^{k+1}$ is the update velocity for each particle

Step 7. If Particle position is greater than or equal to bounds in (12) then stop otherwise go to step 2

\section{RESULTS AND DISCUSSION}

This section illustrates implementation of DOMSOBAELD algorithm on 6 unit, 30 bus IEEE test case system shown in Figure 1 for forming the combined objective function involving cost and emission level function through a price penalty factor for mitigating the transmission losses and multi constraints through valve point loading (VPL) effect shown in Figure 2 and prohibited operating zones (POZ) marked in Figure 3. Table 1 shows cost coefficient, emission coefficient, minimum and maximum capacity of generating units for cost and emission function. Flow chart for DOMSOBAELD algorithm is presented in Figure 4.

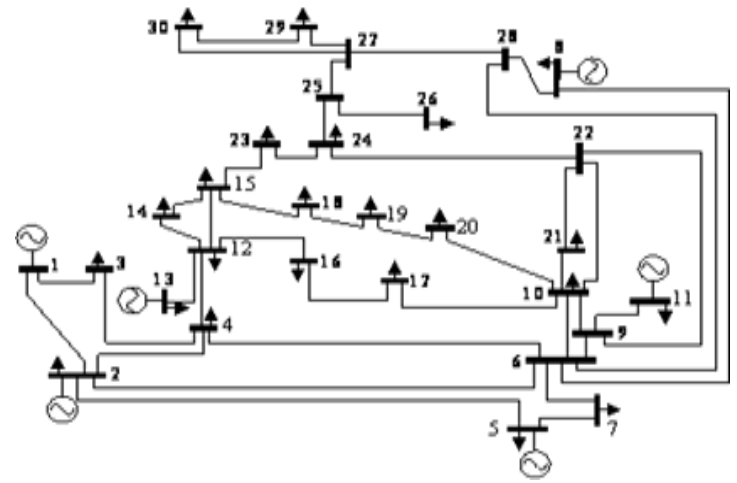

Figure 1. IEEE 30 bus test case systems for DOMSOBAIELD approach

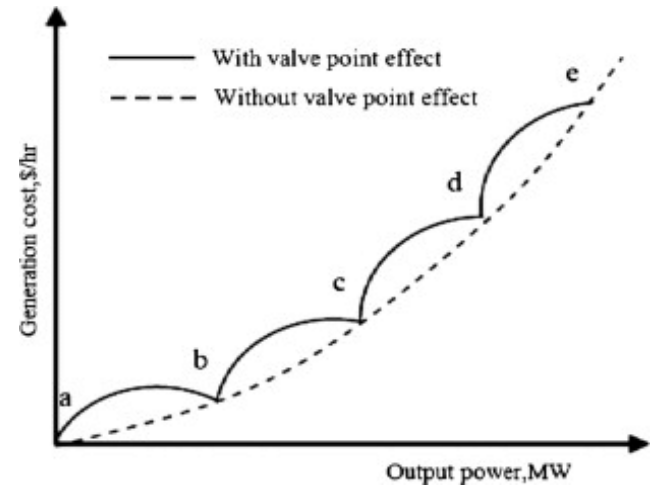

Figure 2. Multi-valve effect of turbine generator units

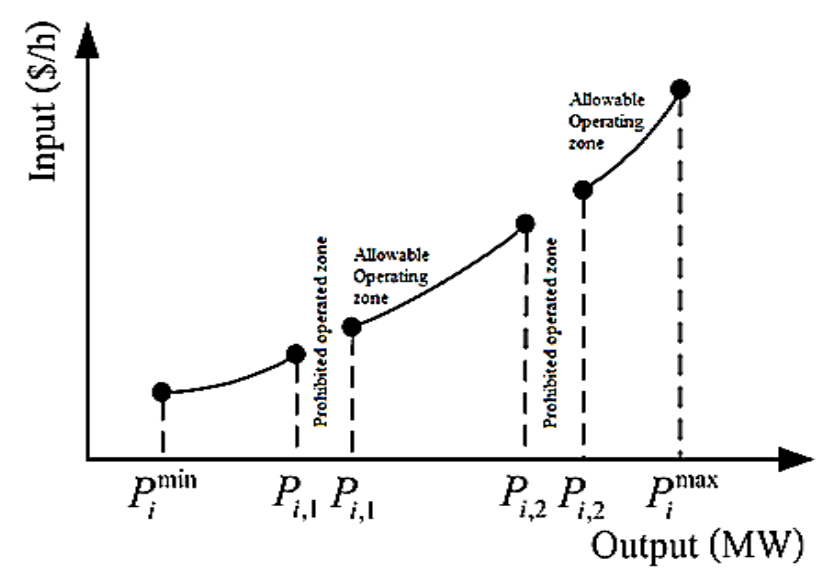

Figure 3. Input output characteristic of generating units with prohibited operating zones

Table 1. Cost coefficients, unit capacity and emission coefficients for IEEE 30 bus test case system with 6

\begin{tabular}{lccccccccc}
\multicolumn{8}{c}{ generating units } \\
\hline Unit & $a_{i}$ & $b_{i}$ & $c_{i}$ & $P_{i \max }=P_{i}$ & $P_{i \min }=P_{i}$ & \multicolumn{1}{c}{$h_{i}$} & $g_{i}$ & $q_{i}$ \\
\hline 1 & 0.1424 & 37.439 & 755.80 & 125 & 15 & 0.0039 & 0.3266 & 13.84932 \\
2 & 0.0958 & 45.144 & 455.325 & 170 & 10 & 0.0040 & 0.32667 & 13.84932 \\
3 & 0.0180 & 39.385 & 1048.88 & 225 & 30 & 0.00673 & 0.54771 & 40.2709 \\
4 & 0.0025 & 37.304 & 1235.55 & 235 & 30 & 0.00103 & 0.54 .651 & 40.2709 \\
5 & 0.0111 & 35.326 & 1656.56 & 320 & 135 & 0.00501 & 0.5119 & 42.88553 \\
6 & 0.0169 & 37.250 & 1355.65 & 390 & 130 & 0.00501 & 0.5119 & 42.88553 \\
\hline
\end{tabular}




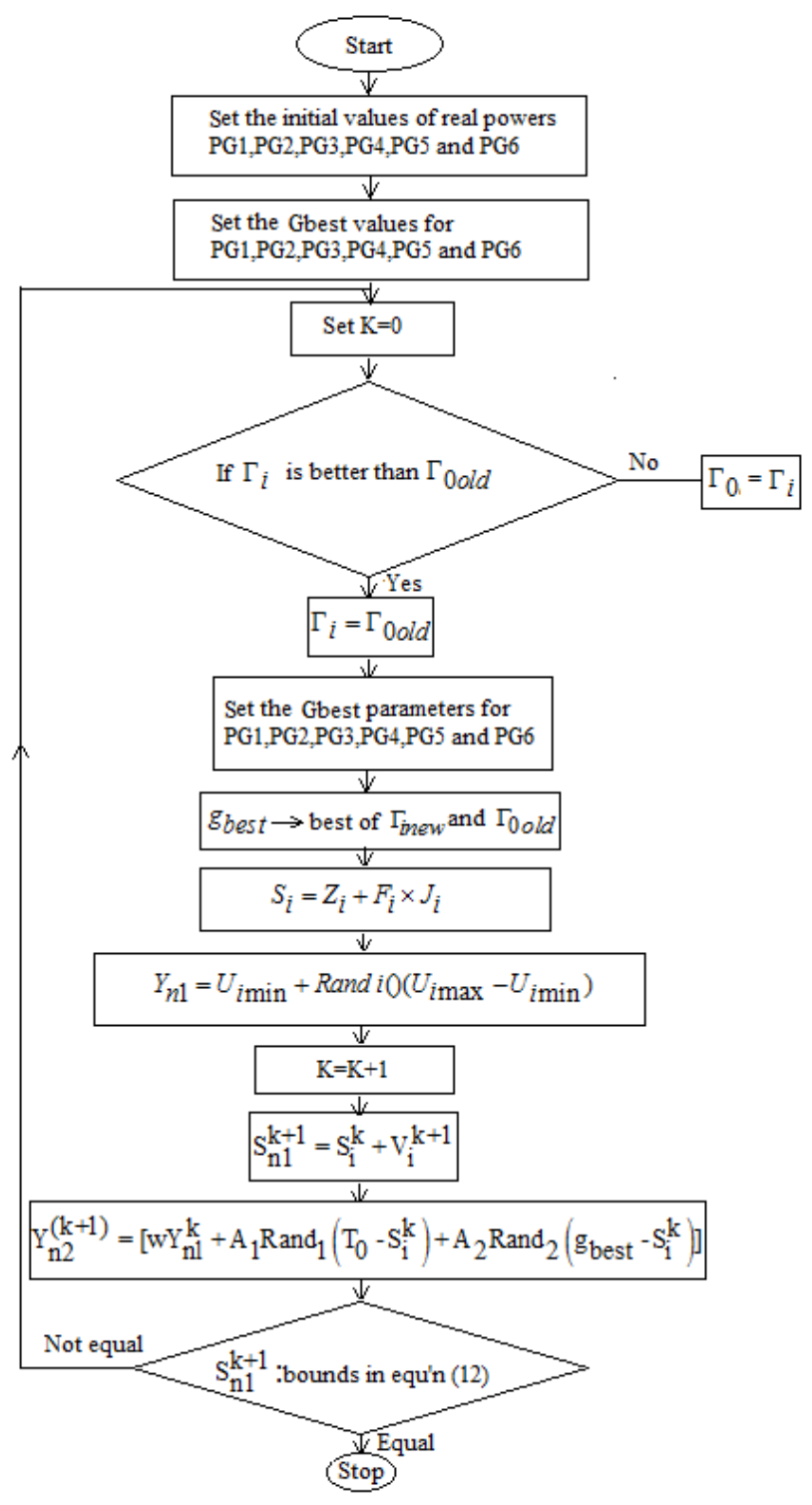

Figure 4. Flow chart for DOMSOBAELD method

Figure 5 shows the simulink model for various objectives of the proposed thermal power plant. Optimal parameters for thermal power plant and the loss coefficients for 6 unit system for inclusion of transmission loss are presented vide Tables 2 and 3 respectively. In this method initial values of real powers for 6 generating units are obtained by simulating the thermal power plant outages involving all the constraints in form an integro differential equation involving automatic load frequency parameters and automatic voltage regulator loop parameters shown in Table 4. These values of real power generations are considered as the initial fitness variables for PSO and using them the final gbest values are obtained and updated particle position and velocities are obtained to estimate the final values of cost, emission and combined objective functions shown in Figures 6-8. The results shown in Figures 6-8 suggest that beyond $200 \mathrm{MW}$, cost, emission level referred through [16] as well as total objective function yield better performance over the classical methods like lambda iteration, mixed integer with linear programming (MILP) method and quadratic method because of updation of swarm position i.e. $S_{n 1}(k+1)=S_{i}^{k}+Y_{n 2}^{(k+1)}$. It also outperforms heuristic methods like PSO [17-21] PSOIW [22, 23], constriction factor based particle swarm optimization (CPSO) [24] and DPSO [25]. and the results are tabulated in Table 5. Valve point loading effects of turbines [26] and prohibited operating zones analysis [27] are effectively dealt in this dissertation. The ramp rate constraints and multi-valve effects $[28,29]$ are of paramount importance in realizing the DOMSOBAELD approach. 


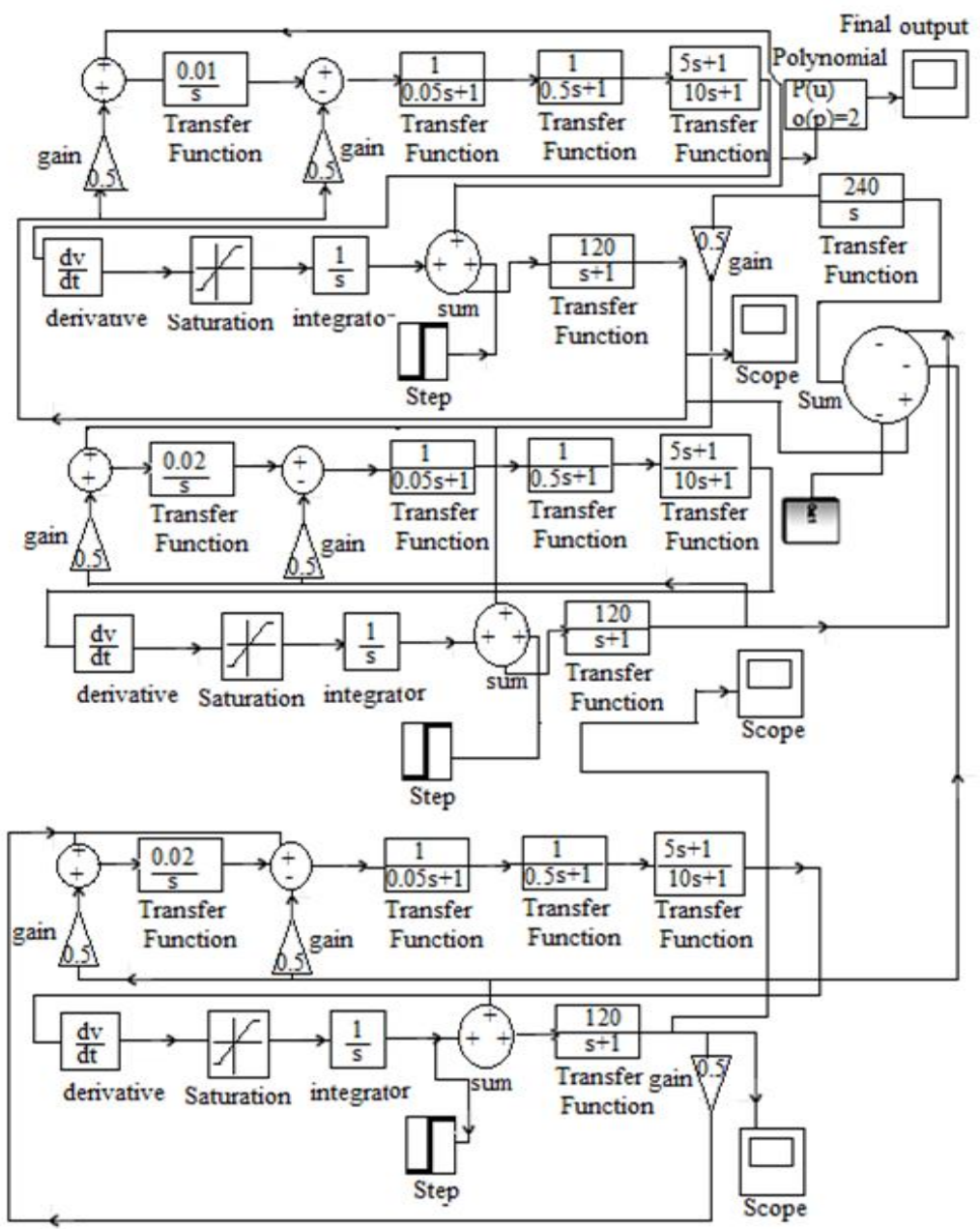

Figure 5. Simulink model for various objectives for a thermal power plant

Table 2. Optimal system parameter incorporating transmission loss

\begin{tabular}{cccc}
\hline SL.No. & Description of parameters & Symbol used & $\begin{array}{c}\text { Optimal value of } \\
\text { parameters }\end{array}$ \\
\hline 1 & Constriction factor & $\mathrm{CF}$ & 2.9 \\
2 & Acceleration coefficients & $\mathrm{A} 1, \mathrm{~A} 2$ & 2.1 \\
3 & Minimum Inertia weight & $W_{\min }$ & 0.35 \\
4 & Maximum Inertia weight & $w_{\max }$ & 0.85 \\
5 & Number of iterations & $\mathrm{K}$ & 100 \\
6 & Random values & $R_{1}, R_{2}, R_{i}$ & $0.3,0.7,0.5$ \\
7 & Power Demands & $\mathrm{PD}$ & $1200 \mathrm{MW}$ \\
8 & Power generation of $i^{\text {th }}$ unit just before the current & $P_{i 0}$ & 80 \\
& interval & & \\
9 & Down ramp rate limit of $i^{t h}$ unit & $D R_{i}$ & 44 \\
10 & UP ramp rate limit of $i^{\text {th }}$ unit & $U R_{i}$ & 1244 \\
\hline
\end{tabular}

Table 3. Transmission loss coefficient for 6 unit test

\begin{tabular}{ccccccc}
\multicolumn{7}{c}{ case thermal system } \\
\hline Unit & 1 & 2 & 3 & 4 & 5 & 6 \\
\hline 1 & 1.39 & 0.16 & 0.14 & 0.18 & 0.25 & 0.21 \\
2 & 0.16 & 0.59 & 0.12 & 0.15 & 0.14 & 0.19 \\
3 & 0.14 & 0.12 & 0.64 & 0.16 & 0.23 & 0.18 \\
4 & 0.18 & 0.15 & 0.16 & 0.61 & 0.29 & 0.24 \\
5 & 0.25 & 0.14 & 0.23 & 0.29 & 0.68 & 0.31 \\
6 & 0.21 & 0.19 & 0.18 & 0.24 & 0.31 & 0.84 \\
\hline
\end{tabular}

Table 4. Parameters of 6 unit test case thermal

\begin{tabular}{l}
\multicolumn{1}{c}{ system } \\
\hline System Frequency $(\mathrm{f})=60 \mathrm{HZ}$ \\
$T g 1=T g 2=0.8 \mathrm{~S}$ \\
$P$ tie $\max =350 \mathrm{MW}$ \\
$\operatorname{Tr} 1=\operatorname{Tr} 2=10 \mathrm{~S}$ \\
$\operatorname{Kr} 1=K r 2=0.5$ \\
$T t 1=T t 2=0.3$ \\
$K p 1=K p 2=120 \mathrm{~Hz} / \mathrm{PU} \mathrm{MW}$ \\
$\operatorname{Tp} 1=T p 2=1 S, a=-0.5 ; a 12=-0.5$ \\
\hline
\end{tabular}




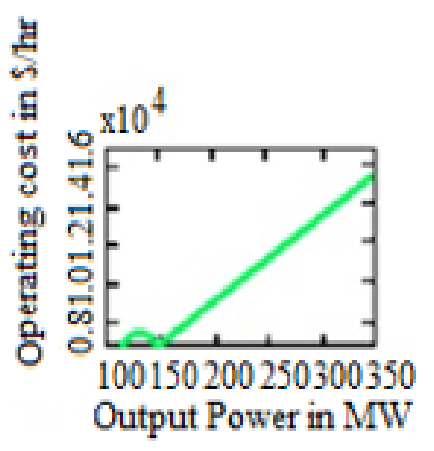

Figure 6. Operating cost function vs output power

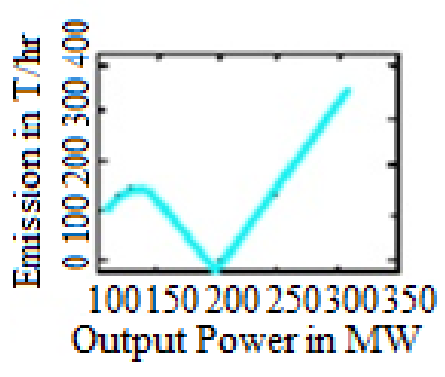

Figure 7. Emission level vs. output power

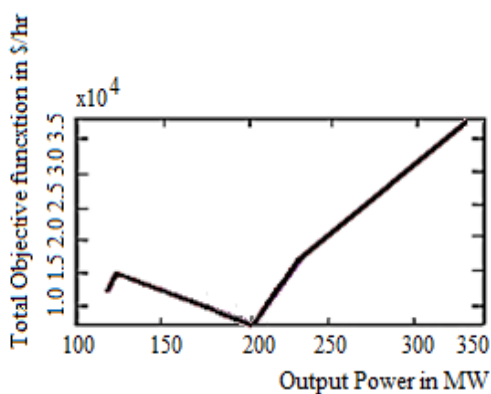

Figure 8. Total objective function vs. output power

Table 5. Result of 6 unit systems for a load demand of 1200 MW

\begin{tabular}{ccccc}
\hline Unit Output & PSO & PSOIW & DPSO & DOMSO BAELD \\
\hline PG1 (MW) & 49.22 & 50.02 & 93.02 & 120 \\
PG2 (MW) & 18.84 & 20.88 & 100.02 & 130 \\
PG3 (MW) & 108.85 & 110.09 & 95.00 & 150 \\
PG4 (MW) & 58.88 & 60.34 & 150.47 & 200 \\
PG5 (MW) & 208.81 & 210.62 & 200.05 & 250 \\
PG6 (MW) & 307.13 & 308.58 & 270.55 & 350 \\
Loss (MW) & 53.78 & 56.89 & 60.57 & 45.59 \\
Total Power Output & 807.51 & 819.42 & 971.68 & 1200 \\
Fuel cost (\$/hr) & 61115 & 61209 & 63629.2 & 59626 \\
Emission (T/hr) & 1026.23 & 1033.47 & 1043.458 & 1020.3 \\
Total cost (\$/hr) & 100611 & 100719 & 100611 & 100922 \\
\hline
\end{tabular}

\section{ANALYSIS OF VARIOUS OBJECTIVE FUNCTIONS}

Various objectives targeted through DOMSOBAELD optimization approach were found to satisfy various nonlinear constraints like prohibited operating zones, valve point loading and Ramp rate constraints along with equality and inequality constraints. The results obtained through a P5 machine employing Matlab 2016 yields better result in comparison to other heuristic methods for optimum operating cost, emission level and total objective function with respect to real power variation of various generating units.

\section{CONCLUSION}

The DOMSOBAELD technique illustrated an advanced PSO technique involving multi valve effects, droop constraints and power system swarm optimization tool box for analysing the economic dispatch problem and the results were verified with other heuristic methods using matlab simulation for multi-objective problem involving particle swarm optimization technique, PSOIW technique and differential particle swarm optimization technique. The simulink model is used for comparing the results of various heuristic methods described earlier. The optimal values of generating units $t$ give rise to cost of generation, emission level and combined objective response in DOMSOBAELD analysis. This method proved to be efficient and beneficial over lambda iteration method, mixed integer linear programming method (MILP), quadratic programming method and soft computing methods like particle swarm optimization, constriction factor based particle swarm optimization (CPSO) and differential particle swarm optimization (DPSO). in terms of convergence time for most favourable solution. The DOMSOBAELD technique would be applied to electromagnetic based particle swarm optimization dispatch problems in upcoming paper involving formidable prohibited operating zones. The recent work has basic constraints like valve point loading resulted out of multi-valve effect, ramp rate constraints, less formidable prohibited operating zones, equality and inequality constraints. However, this method in conjunction with electromagnetic based dispatch can be utilized to handle constraints coming out of tie line in multi area economic dispatch, multi fuel option constraint, penalty factor constraint and different tie line capacity constraints resulted out of varying load behaviour. The correlation of particle position and particle velocity with aforesaid multiple constraints decides and $\mathrm{P}$ best values which are not being used by any other heuristic methods. As a result of this, fast convergence is obtained in this method resulting thereby better simulation results so as to reduce simulation time required for obtaining response characteristic of system model involving multiple heuristic subsystems. 


\section{ACKNOWLEDGEMENTS}

We would like to extend our gratitude to supreme soul Shreema (The Mother) for constantly motivating us through her meditation principles to go for this research work for welfare of nation against global warming. Apart from this we deeply acknowledge the motivational talks and all round support of Prof. Dr. Chandradhwaj Panda (Honourable Secretary of GITA, Bhubaneswar) without which this research work would not have been complete.

\section{REFERENCES}

[1] N. Singh and Y. Kumar, "Economic Load Dispatch with Valve Point Loading Effect and Generator Ramp Rate Limits Constraint using MRPSO," International Journal of Advanced Research in Computer Engineering \& Technology (IJARCET), vol. 2, no. 4, pp. 1472-1477, 2013.

[2] Parmvir Singh Bhullarr and Jaspreet Kaur Dhami, "particle swarm optimization based economic load dispatch with valve point loading," International Journal of Engineering Research \& Technology, vol. 4, no. 5, pp. 1064-1070, 2015.

[3] He Da-kuo, Wang Fu-li, MaoZhi-zhong, "Hybrid genetic algorithm for economic dispatch with valve-point effect," Electric Power Systems Research, vol. 78, no. 4, pp. 626-633, 2008.

[4] Bo Li, Yudong Wang, Jian Li and Shengxian Cao, "A Fully Distributed Approach for Economic Dispatch Problem of Smart Grid," Energies, vol. 11, no. 8, p. 1993, 2018.

[5] Li, Z. G., Wu, W. C., Zhang, B. M., Sun, H. B., Guo, Q. L., "Dynamic economic dispatch using Lagrangian relaxation with multiplier updates based on a quasi-newton method," IEEE Transactions on Power Systems, vol. 28, no. 4, pp. 4516-4527, 2013

[6] Hemamalini, S., Simon, S. P., "Dynamic economic dispatch using Maclaurin series based Lagrangian method," Energy Conversion and Management, vol. 51, no. 11, pp. 2212-2219, 2010.

[7] Muhamad Hazim Lokman, Ismail Musirin, Saiful Izwan Suliman, Hadi Suyono, Rini Nur Hasanah, Sharifah Azma Syed Mustafa and Mohamed Zellagui, "Multi-verse optimizati-on based evolutionary programming technique for power scheduling in loss minimization scheme," International Journal of Artificial Intelligence (IJ-AI), vol. 8, no. 3, pp. 292-298, 2019.

[8] Zhang, X., Wang, D., \& Chen, H., "Improved Biogeography-Based Optimization Algorithm and Its Application to Clustering Optimization and Medical Image Segmentation," IEEE Access, vol. 7, pp. 28810-28825, 2019.

[9] C. helladurai and A. A. Victoire, "Crisscross Optimization with Comprehensive Vertical Crossover to Solve Combined Economic Emission Dispatch," Advances in Electrical and Computer Engineering, vol. 18, no. 3, pp. 131-140, 2018.

[10] V. Hemanth Kumar, P. SrinivasaVarma, T. Bharath Kumar, E. Sreelatha, "Economic and Emission Dispatch Probelmusing particle swarm optimization," International journal of Innovative Technology and Exploring Engineering and Technology,(IJITEE), vol. 8, no. 6, pp. 939-944, 2019.

[11] Ansil Sharma and Govind R. Goyal, "Solution of an ELD problem with valve-point effect using artificial intelligence techniques," International information and Engineering Technology Association journal, vol. 4, no. 3, pp. 132-138, 2017.

[12] Chao Fu, Suqi Zhang, Kuei-Hsiang Chao, "Energy Management of a Power System for Economic Load Dispatch Using the Artificial Intelligent Algorithm,” Electronics, vol. 9, pp. 1-19, 2020.

[13] Dipankar Santra; Krishna Sarker, Anirban Mukherjee, Subrata Mondal, "Combined economic emission and load dispatch using hybrid metaheuristics," International Journal of Hybrid Intelligence, vol. 1, no. 2-3, pp. 211-238, 2019.

[14] R. Eberhart, J. Kennedy, Wameedh Riyadh Abdul-Adheem, "An enhanced particle swarm optimization algorithm," International Journal of Electrical and Computer Engineering (IJECE), vol. 9, no. 6, pp. 4904-4907, 2019.

[15] AshitaDutta, Ann Susan Luke, Samya Kumar Gupta, P. Tejasree, ShivamShukla, Vishwajeet Kumar, P. Suresh,“ Modified Particle Swarm Optimisation for Economic Load Dispatch Problem,” International Journal of Recent Technology and Engineering (IJRTE), vol. 8, no. 2S3, pp 172-177, 2019.

[16] Maharnad Nabab Alarn, Akhilesh Mathur and Kanhaiya Kurnar, "Economic Load Dispatch using a Differential Particle Swarm Optimization," 2016 IEEE 1st International Conference on Power Electronics, Intelligent Control and Energy Systems (ICPEICES), Delhi, 2016, pp. 1-5.

[17] Maedeh Gholamghasemia, Ebrahim Akbarib, Mohammad, Bagher Asadpoorc and Mojtaba Ghasemi, "A new solution to the non-convex economic load dispatch problems using phasor particle swarm optimization," Applied Soft Computing, vol. 79, pp. 111-124, 2019.

[18] Tan Minh Phan, Phu Trieu Ha, Thanh Long Duong, Thang Trung Nguyen, "Improved particle swarm optimization algorithms for economic load dispatch considering electric market," International Journal of Electrical and Computer Engineering (IJECE), vol. 10, no. 4, pp. 3918-3926, 2020.

[19] Mohammed Amine Meziane, Youssef Mouloudi, Bousmaha Bouchiba, abdellah Laoufi "Impact of inertia weight strategies in particle swarm optimization for solving economic dispatch problem," Indonesian Journal of Electrical Engineering and Computer Science, vol. 13, no. 1, pp. 377-383, 2019.

[20] Huazhen Cao, Tao Yu, Xiaoshun Zhang, Bo Yang, and Yaxiong Wu, "Reactive Power Optimization of Large-Scale Power Systems: A Transfer Bees Optimizer Application,” Processes, vol. 7, no. 6, pp. 1-17, 2019.

[21] Kyaw Myo Lin, Pyone Lai Swe, Khine Zin oo, "Optimal Distributed Generator Sizing and Placement by Analytical Method and PSO Algorithm Considering Optimal Electronics and Communication Engineering," World Academy of Science, Engineering and Technology International Journal of Efectronics and Comunnication Engineering, vol. 13, no. 1, pp. 13-20, 2019. 
[22] B. Dogan, T. Olmez, "A New Metaheuristic for Numerical Function Optimization: Vortex Search Algorithm," Information Sciences, vol. 293, pp. 125- 145, 2015.

[23] Imam Tahyudin, Hidetaka Nambo, "Improved optimization of numerical association rule mining using hybrid particle swarm optimization and cauchy distribution," International Journal of Electrical and Computer Engineering (IJECE), vol. 9, no. 2, pp. 1359-1373, 2019.

[24] Mohammadi-Ivatloo, M. Moradi-Dalvand, and A. Rabiee, "Combined heat and power economic dispatch problem solution using particle swarm optimization with time varying acceleration coefficients," Electric Power Systems Research, vol. 95, pp. 9-18, 2013.

[25] Shi C. C., Chun H. C., Fomg I. K. and Lah P. B., "Hydroelectric generation scheduling with an effective differential dynamic programming algorithm," IEEE transaction on power system, vol. 5, no. 3, pp. 737-743, 1990.

[26] Mallikrjuna Bestha, K. Harinath Reddy, O. Hemakeshavulu, "Economic Load Dispatch Downside with ValvePoint Result Employing a Binary Bat Formula," International Journal of Electrical and Computer Engineering (IJECE), vol. 4, no. 1, pp. 101-107, 2014.

[27] P. K. Hota, et al., "Non-Convex Economic Dispatch with Prohibited Operating Zones through Gravitational Search Algorithm," International Journal of Electrical and Computer Engineering (IJECE), vol. 5, no. 6, pp. 1234-1244, 2015.

[28] Himanshu Shekhar Maharana, S. K. Dash, "Ramp Rate and Constriction Factor Based Dual Objective Economic Load Dispatch Using Particle Swarm Optimization," World Academy of Science, Engineering and Technology,International Science Index, Energy and Power Engineering, vol. 11, no. 6, pp. 636-640, 2017.

[29] Ahmet Dogan, Serkan Bahceci, Ferhat Daldaban and Mustafa Alci, "Optimization of Charge/Discharge Coordination to Satisfy Network Requirements Using Heuristic Algorithms in Vehicle-to-Grid Concept," Advances in Electrical and Computer Engineering, vol. 18, no. 1, pp. 121-130, 2018.

\section{BIOGRAPHIES OF AUTHORS}

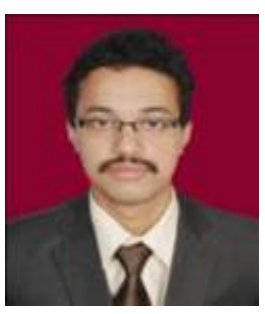

Himanshu Shekhar Maharana completed his Masters Programme in Power System Engineering from GITA, Bhubaneswar under BPUT Odisha, in the year 2014. Prior to it he worked in industry. At present he is continuing full time Ph.D. in Biju Patnaik University of Technology, Odisha under the guidance of Professor Dr. S. K. Dash.

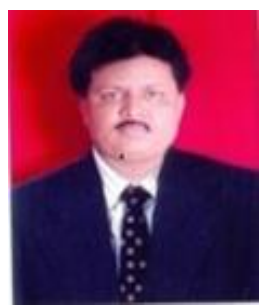

S. K. Dash received the UG degree in Electrical Engineering from I.E, India in 1991 and accomplished Master's Program in electrical engineering from UCE, Burla (Sambalpur University), India, in 1998 and the $\mathrm{PhD}$ degree from Utkal University, Odisha, India in the year 2006. He has been with the Electrical Engineering Department, Gandhi Institute for Technological Advancement as a Professor and Head of the Department since 2005.Prior to it he worked in industry for 5 years and in OSME, Keonjhar, for 2 years and in Krupajal Engineering College for 4 years. His research areas include power system planning, operation, and optimization techniques relating to economic dispatch of electric power system. Dr. Dash received Pundit Madan Mohan Malaviya award, Union Ministry of Power Prize and gold medals thereof for his research papers entitled "Economic load dispatching of generating units with multi-fuel options" and "Short term generation scheduling with take or pay fuel contract using evolutionary programming technique "on Multi Objective Generation Dispatch. He too authored two books entitled 'Fundamentals of Electromagnetic Field Theory and 'Basic Electrical Engineering under the umbrella of PHI Publication and YESDEE publication in the year 2010 and 2016 respectively. Dr. Dash is engaged as a reviewer of EPCS, and EPSR journals of IEEE. He is the recipient of best session chair award in the World Academy of Science, Engineering and Technology (WASET) Conference held in SANFRANCISCO, USA during 7th June 2017 and also received thereof best paper presentation award for two of his research papers on PSO and EP. He is too awarded with energy conservation award in the year 2015 and 2016 as well for bringing solar power plants in GITA, Bhubaneswar. 